\title{
HIDRÓLISE DO ÓLEO DE CRAMBE EMPREGANDO LIPASE VEGETAL EXTRAÍDA DE SEMENTES DE DIFERENTES OLEAGINOSAS
}

\author{
F. TAVARES ${ }^{1}$, P. SACKSER ${ }^{1}$, F. PINZAN ${ }^{1}$, C. E. BORBA e E. A. SILVA ${ }^{1}$ \\ ${ }^{1}$ Universidade Estadual do Oeste do Paraná, Departamento de Engenharia Química \\ E-mail para contato: fernandatavareseq@hotmail.com
}

\begin{abstract}
RESUMO - Atualmente a rota mais utilizada para a produção do biodiesel é a transesterificação homogênea, processo que envolve alto custo quanto ao processo de separação e purificação do biodiesel/glicerina e por demandar que a matériaprima seja refinada. A hidroesterificação é uma alternativa que envolve uma etapa de hidrólise seguida de esterificação. A hidrólise consiste na reação entre o óleo com a água, gerando glicerina e ácidos graxos. O uso de enzimas como catalisadores oferece vantagens em relação ao processo químico, fazendo com que a reação aconteça em condições brandas de pressão e temperatura. Lipases, catalisadores de reações de hidrólise, podem ser obtidas de fontes microbianas, animais e vegetais, sendo que as microbianas são a grande maioria produzida atualmente e apresentam alto custo de produção, favorecendo o estudo de fontes vegetais. Entre as fontes alternativas de matéria-prima para a produção de biodiesel encontra-se o crambe que, devido a sua riqueza em óleo vegetal e custos de produção relativamente baixos, representa uma opção para esse uso. Sendo assim, o presente trabalho visou estudar a utilização de extrato de sementes de soja, crambe e mamona na hidrólise do óleo de crambe. A única semente estudada a apresentar lipase com atividade considerável foi a semente de mamona que resultou em aproximadamente $60 \%$ de acidez ao final de $2,5 \mathrm{~h}$ de reação em meio de $\mathrm{pH} 4,0$.
\end{abstract}

\section{INTRODUÇÃO}

As pesquisas na área de combustíveis renováveis têm aumentado nos últimos anos devido às preocupações com o meio ambiente, em particular, o biodiesel tem sido amplamente estudado devido à variedade de matérias-primas, bem como os diferentes processos possíveis para a produção. $\mathrm{O}$ processo industrial atualmente mais utilizado para a produção de biodiesel é a transesterificação alcalina homogênea de óleos comestíveis, que tem um alto rendimento (cerca de $98 \%$ ) e curto tempo de reação (cerca de 1 h). No entanto, este processo tem algumas desvantagens: dificuldade de separar o catalisador a partir do glicerol, a produção de água residual altamente alcalina e exigência de matérias-primas de alta qualidade com baixo teor de ácidos gordos livres (AGL) (acidez inferior a 0,5\%) e água a fím de evitar a formação de sabão. Estes óleos refinados são relativamente caros e seus preços correspondem a $70-80 \%$ do total do custo da produção do biodiesel, o que torna a comercialização do biodiesel economicamente difícil. (Robles-Medina et al., 2009) 
Crambe Abyssinian, um membro da família Brassicaceae, é uma cultura de óleo que se originou na região do Mediterrâneo (Leppik e White, 1975). Por ser rico em ácidos graxos monoinsaturados (cerca de 75\%) e do seu elevado teor de ácido erúcico (C22: 1), 57,8\%, em média, o óleo é inadequada para consumo humano e tem uma gama promissora de aplicações na indústria oleoquímica (Leonard, 1993). E também é uma matéria-prima interessante para a produção de biodiesel (Mandal et al, 2002). Segundo Lazzeri et al., 1994, as propriedades físicas desse óleo fazem ele interessante para lubrificação, agentes emulsionantes e para refrigeração.

A semente de crambe apresenta elevado teor de óleo (23-38\%) e tem um rendimento médio de sementes de $1.800-2.400 \mathrm{~kg} /$ ha (Carlson et al, 1996). O crambe é uma cultura muito tolerante à seca, principalmente a partir de seu desenvolvimento vegetativo quando não tolera períodos chuvosos ou de alta umidade relativa do ar. É muito tolerante ao frio, exceto após a germinação, quando tolera temperaturas de até $-3^{\circ} \mathrm{C}$ (Pitol, 2008).

A etapa de hidrólise é realizada por um método químico ou enzimático. Uma vez que a hidrólise química envolve a altas temperaturas e altas pressões, as enzimas são uma boa alternativa para o processo. Segundo Posorske (1984), as enzimas têm vantagens para o processamento industrial, como a especificidade que permite o controle dos produtos produzidos e pode também aumentar o rendimento através da redução da quantidade de produtos secundários; condições amenas, o que pode diminuir o custo em termos de equipamento de energia e de capital além de reduzir os custos de tratamento de resíduos. Lipases (hidrolases do éster de glicerol) são um grupo de enzimas que catalisam reações de hidrólise, esterificação, e as reações de transesterificação. Eles atuam em vários compostos de éster, e seus substratos naturais são acilgliceróis (Verger, 1997).

Lipases podem ser obtidas de tecidos vegetais e animais ou produzidas por fermentação de fungos e bactérias. $\mathrm{O}$ alto custo de isolamento e purificação de enzimas microbianas e animais podem restringir sua aplicação industrial em larga escala. Entretanto, esse custo pode ser reduzido pelo uso de lipases vegetais, que podem ser obtidas a partir de fontes renováveis produzidas em larga escala e as quais não exigem alto custo de purificação (Caro et al., 2000).

Sendo assim, o presente trabalho teve por objetivo estudar a hidrólise do óleo de crambe a partir do uso de sementes vegetais como fonte de lipase para catálise da reação. Três sementes foram testadas, sendo elas crambe, soja e mamona.

\section{METODOLOGIA}

Os experimentos foram realizados em laboratório pertencente a Universidade Estadual do Oeste do Paraná - Campus Toledo / PR. O óleo de crambe foi gentilmente doado pela fundação de pesquisa MS que está localizado em Maracaju/MS. As sementes de mamona comercial (Espécie: Ricinus communis L., Cultivar: IAC GUARANI) (Brseeds $\left.{ }^{\circledR}\right)$ foram adquiridas e acetona PA (Vetec) foi utilizada para extração da enzima. Uma solução de fenolftaleína (Synth $\left.{ }^{\circledR}\right)$ foi utilizada como indicador para a medição da acidez do óleo. Etanol absoluto (JTBaker) e éter etílico PA (Vetec) foram usadas no processo de medição. $\mathrm{NaOH}$ (Synth®) foi utilizado para a determinação da acidez. 


\subsection{Preparo dos catalisadores}

A lipase utilizada como catalisador das reações de hidrólise foi extraída das sementes de mamona. Foram adicionados em um triturador aproximadamente 100 gramas de semente com acetona. Emergiu-se a amostra em um béquer novamente em solução de acetona e incubou-se por 16 horas, sob refrigeração. Após esse procedimento, a amostra foi deixada em temperatura ambiente e exposta, de modo a evaporar a acetona residual, secando a amostra. A enzima foi mantida em refrigeração até seu uso.

\subsection{Reações de hidrólise}

Para determinar se as sementes escolhidas apresentam atividade enzimática para a reação de hidrólise de óleo de crambe testes foram conduzidos em um reator (Erlenmeyer $125 \mathrm{~mL}$ ) com agitação de $1000 \mathrm{rpm}$ e temperatura ambiente (aproximadamente $28^{\circ} \mathrm{C}$ ). As quantidades precisas de óleo $(10 \mathrm{~g})$ e enzima $(2 \mathrm{~g})$ foram pesadas em uma balança de precisão e colocadas diretamente no reator. $6 \mathrm{~mL}$ de uma solução tampão de $\mathrm{pH}$ de valor prédeterminado foi inserida no reator, iniciando a reação a temperatura ambiente de aproximadamente $28^{\circ} \mathrm{C}$. Após $2,5 \mathrm{~h}$, colocou-se a amostra em um tubo e centrifugou-se por 5 min e $3000 \mathrm{rpm}$.

A atividade das enzimas foi verificada na faixa de $\mathrm{pH}$ entre 3 e 10. Soluções tampões de acetato para $\mathrm{pH}$ ácido e tampões de amônia foram empregadas.

\subsection{Quantificação da acidez}

A determinação da quantidade de ácidos graxos livres presentes no óleo foi realizada por titulação com solução de $\mathrm{NaOH}$ (Synth $\left.{ }^{\circledR}\right)$. Cerca de $1 \mathrm{~g}$ de óleo e duas gotas de solução de fenolftaleína foram diluídos em $15 \mathrm{ml}$ de 1:1 de etanol/éter. Esta solução foi titulada com uma solução de $\mathrm{NaOH}$ 0,1 M sob agitação vigorosa até a mudança de cor (mudança brusca de cor branca a rosa). Acidez de óleo foi calculada de acordo com a seguinte relação:

$$
\text { Acidez }=100 \cdot \frac{\text { Vol. }_{M_{\mathrm{NaOH}}} \cdot M M_{A G L}}{p}
$$

A massa molecular da AGL foi calculada como uma média ponderada pela fração molar do peso molecular dos ácidos graxos constituintes de óleo de crambe $\left(M M_{A G L}=315,4168\right.$ $\mathrm{g} / \mathrm{mol})$.

\section{RESULTADOS E DISCUSSÃO}

\subsection{Sementes de crambe e soja}

As Figuras 1 e 2 apresentam os resultados da acidez nos testes de hidrólise do óleo de crambe empregando como catalisador sementes de crambe e soja trituradas, respectivamente. Observa-se que praticamente não houve alteração da acidez ao longo de toda a faixa de $\mathrm{pH}$ estudada indicando que ambas sementes de crambe e soja da forma como foram utilizadas não apresentaram enzima lipase livre para a catalisar a reação de hidrólise do óleo de crambe. 
Verscovi (2012) estudou a semente de soja como fonte de lipase para reações de hidrólise e alcançou a atividade de $237 \mathrm{U} / \mathrm{g}$ nas condições experimentais de germinação das sementes por 12 horas, extração a $25^{\circ} \mathrm{C}$ por 12 horas, solução salina (fosfato de sódio, pH 7,0) de $100 \mathrm{mM}$ e adição de Tris-HCl (1\%, m/v) no tampão de extração. Observa-se, portanto que a semente apresenta lipase somente quando passa pela germinação, já que o presente trabalho foi feito sem nenhuma germinação prévia e atividade hidrolítica não foi constatada. $\mathrm{Na}$ literatura não foi encontrado nenhum trabalho envolvendo a extração de lipase de sementes de crambe.

Figura 1 - Variação da acidez do óleo hidrolisado de crambe em relação a variação do $\mathrm{pH}$ do substrato empregando pó de semente de crambe como fonte enzimática.

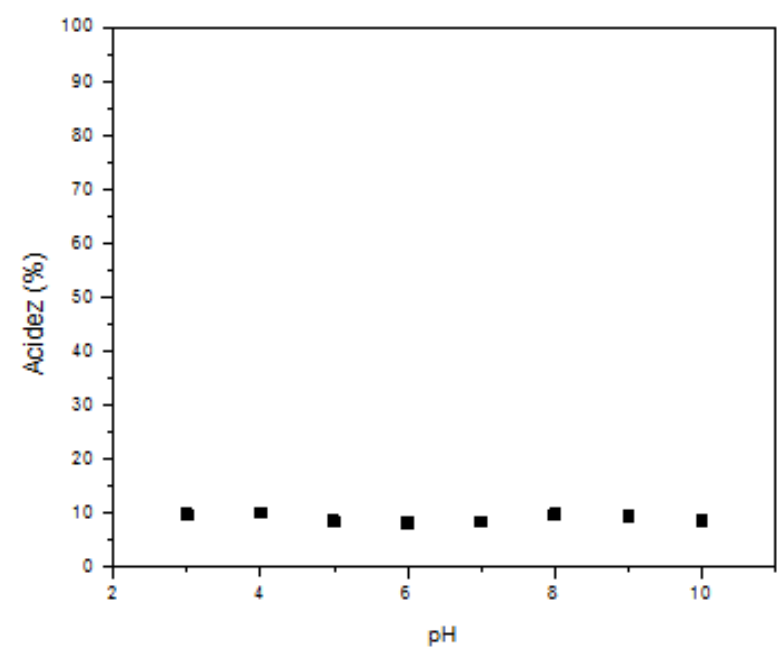

Figura 2 - Variação da acidez do óleo hidrolisado de crambe em relação a variação do $\mathrm{pH}$ do substrato empregando pó de semente de soja como fonte enzimática.

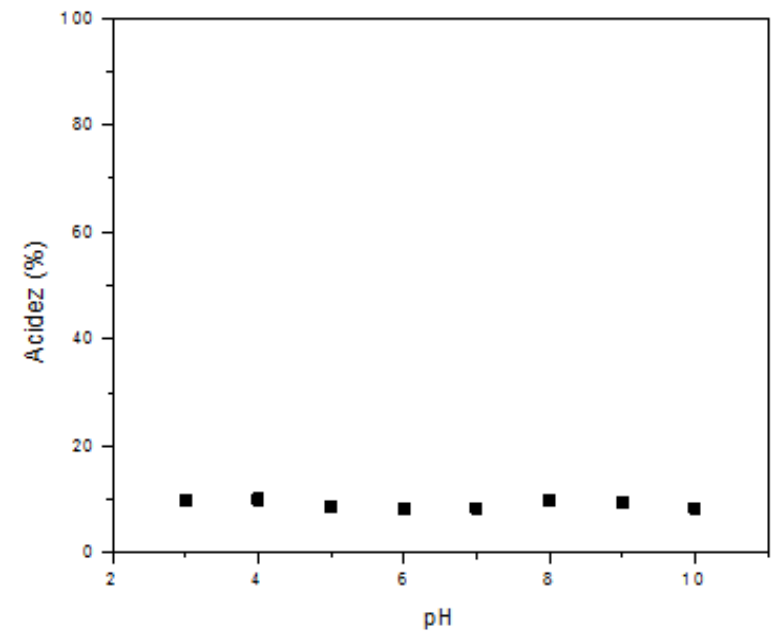

\subsection{Semente de mamona}


A Figura 3 apresenta o resultado da acidez nos testes de hidrólise do óleo de crambe empregando como catalisador o a semente de crambe moída. Observa-se que praticamente não houve alteração da acidez ao longo de toda a faixa de $\mathrm{pH}$ estudada indicando que a semente de crambe da forma como foi utilizada não apresenta enzima lipase livre para a catalisar a reação de hidrólise do óleo de crambe.

Avelar et al. (2012) realizou testes empregando sementes de mamona dormente na hidrólise de óleo de soja, canola e oliva, usando 10 gramas de óleo, $90 \mathrm{~mL}$ de solução tampão de acetato $(\mathrm{pH} 4,5), 2$ gramas de extrato de lipase, temperatura de $25^{\circ} \mathrm{C}$ e rotação de 1000 rpm, atingindo aproximadamente $80 \%$ de acidez para todos os óleos estudados em 3 horas de reação. Observa-se, portanto, que resultados satisfatórios com o uso de sementes de mamona já são encontrados na literatura e a faixa de pH empregada é de $\mathrm{pH}$ 4-5.

Santos et al. (2013) também estudaram diferentes sementes na produção de lipase para hidrólise de diferentes óleos vegetais, em seu estudo constataram que lipases provindas da semente de mamona foram mais eficientes na produção de ácidos graxos livres em comparação com sementes de milho, maracujá e girassol, além disso em concordância com o presente trabalho observaram o $\mathrm{pH}$ ótimo de 4,5 para a lipase de semente de mamona. Ainda, segundo o autor, a aplicação da semente de mamona pode ser economicamente atrativa para a produção de ácidos graxos a partir de triglicerídeos já que as etapas de purificação e imobilização não são requeridas, e as moléculas de lipase são naturalmente imobilizadas dentro do material das sementes.

Figura 3 - Variação da acidez do óleo hidrolisado de crambe em relação a variação do pH do substrato empregando pó de semente de mamona como fonte enzimática.

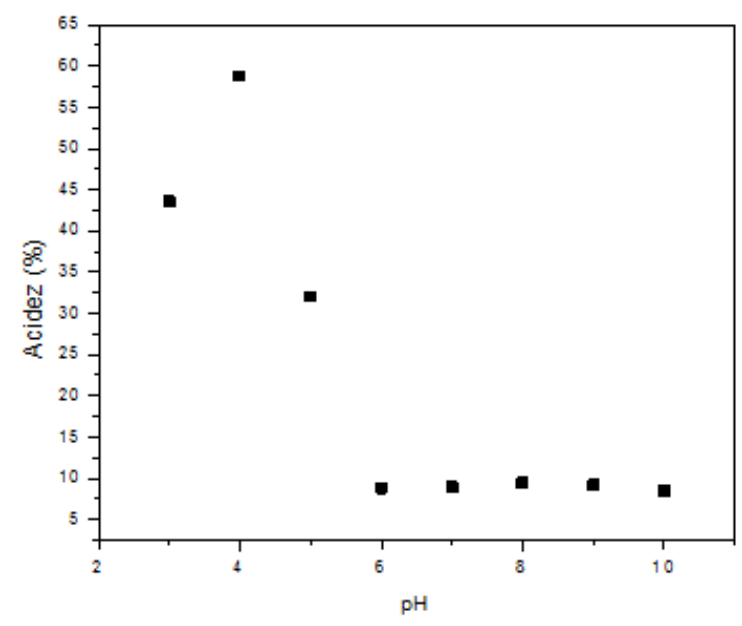

\section{CONCLUSÃO}

O presente trabalho teve como objetivo avaliar sementes de soja, crambe e mamona na extração de lipase para produção de ácidos graxos a partir do óleo de crambe. Todas as sementes foram usadas na forma dormente, sem germinação, e somente a semente de mamona resultou em lipase com atividade considerável, tal lipase teve seu $\mathrm{pH}$ ótimo encontrado no valor de 4,0 e acidez de aproximadamente $60 \%$ foi atingida após $2,5 \mathrm{~h}$ de reação 
demonstrando potencial para o uso dessa fonte, já que possibilita que a hidrólise ocorra em condições amenas de pressão e temperatura além de ter um custo de produção baixo e não precisar de processo prévio de germinação.

\section{REFERÊNCIAS}

AVElAR, M. H., CASSIMIRO, D. M., SANTOS, K. C., DOMINGUES, R. C., DE CASTRO, H. F., MENDES A. A. Hydrolysis of vegetable oils catalyzed by lipase extract powder from dormant castor bean seeds. Ind Crop Prod, v. 44, p. 452-458, 2013.

CARLSON, K.D.; GARDNER, J.C.; ANDERSON,V.L.; HENZEL, J.J.; Crambe: New crop success. In: Janick, J. (Ed.), Progress in New Crops., 306-322, 1996.

CARO, Y. VILLENEUVE, P., PINA, M., REYNES, M., GRAILLE, J. Lipase activity and fatty acid typoselectivity of plants extracts in hydrolysis and intersterification. $\mathrm{J} \mathrm{Am} \mathrm{Oil}$ Chem Soc, v.77, n.4, p.349-354, 2000.

LAZZERI L., LEONI O., CONTE L. S., PALMIERI S.; Some technological characteristics and potential uses of Crambe abyssinica products. Ind Crop Prod, 3, 103-112. 1994.

LEONARD, EC., High-erucic vegetable oils. Ind Crop Prod, 1: 119-123, 1993.

LEPPIK, E.E.; WHITE, G.A.; Preliminary assessment of crambe germplasm resources. Euphytica 24, 681-689. 1975.

MANDAL, S.; SANGITA, Y.; SINGH, R.; BEGUN, G.; SUNEJA, P.; SINGH, M.; Correlation studies on oil content and fatty acid profile of some Cruciferous species. Genet Resour Crop Evol. 49 551-556, 2002.

PITOL, C., Tecnologia e Produção: Milho Safrinha e Culturas de Inverno, 2008.

POSORSKE, L. H.; Industrial-scale application of enzymes to the fats and oil industry. $J \mathrm{Am}$ Oil Chem Soc 61, 1758-1760, 1984.

ROBLES-MEDINA A, GONZÁLEZ-MORENO P. A, ESTEBAN-CERDÁN L, MOLINAGRIMA E. Biocatalysis: towards ever greener biodiesel production. Biotechnol Adv; 27:398-408, 2009.

SANTOS, Kádima C. CASSIMIRO, D. M., AVELAR, M. H., HIRATA, D. B., DE CASTRO, H. F., FERNÁNDEZ-LAFUENTE, R., Mendes, A. A. Characterization of the catalytic properties of lipases from plant seeds for the production of concentrated fatty acids from different vegetable oils. Ind Crop Prod, v. 49, p. 462-470, 2013.

VERGER, R.; "Interfacial activation" of lipases: facts and artefacts. Trends Biotechnol. 15 32-38, 1997.

VESCOVI, V. Extração, purificação e imobilização de lipases vegetais destinadas à síntese de biodiesel e ésteres. Dissertação de mestrado de Engenharia Química da Universidade Federal de São Carlos, São Carlos, São Paulo, 2012. 